Chapter 8

\title{
Policy Arrangement for Waste Management in East Africa's Urban Centres
}

\author{
Christine Majale-Liyala \\ Additional information is available at the end of the chapter \\ http://dx.doi.org/10.5772/54382
}

\section{Introduction}

Today waste management in developing countries and particularly in East Africa is characterised by the involvement of both state and non state actors. The types of arrangement for service provision range from self-provision through collective action independent of external agencies to indirect state provision through sub-contracting to other agencies - NGOs, private for profit companies, user groups among others. Generally, there is much agreement that monopolistic provision realized entirely through state agencies is unfeasible, undesirable, or simply rather old fashioned $[1,2,3]$. However, there is little consensus on the alternative. According to arguments presented by Joshi and Moore in [4], there is need to look beyond new discourses like New Public management and Public Private Partnerships indicating that the trend now is towards pragmatism, pluralism and adaptation to specific circumstances because the reality in such developing countries is highly diverse. Some services, it is argued, cannot be effectively delivered to the ultimate recipients by state agencies because the environment is too complex or variable, and the costs of interacting with very large numbers of poor households are too high. In such cases, users become involved in an organized way at the local level. There are arrangements therefore that do not fit into standard categories. Some of these unorthodox arrangements are of recent origin, and are seen to constitute (smart) adaptations to prevailing local circumstances. They are widespread in developing countries but they raise many issues. This chapter looks at these arrangements through the lens of policy arrangement approach [5] to help discern which arrangement results in better waste management.

The urban centres studied are Mwanza, Kisumu, and Jinja which are considered primary urban centres coming just after the capital cities in their respective countries. The three centres lie within the lake Victoria basin (See Figure 1) and therefore their individual efforts in 
waste management contribute to sustainable management of the lake by among other things, reducing the pollutant load into the Lake. These three were chosen because of certain similarities (and differences) but more so because they are all found on the shores of the lake basin as mentioned earlier and they are all primary urban centers which makes them comparable in urban status.

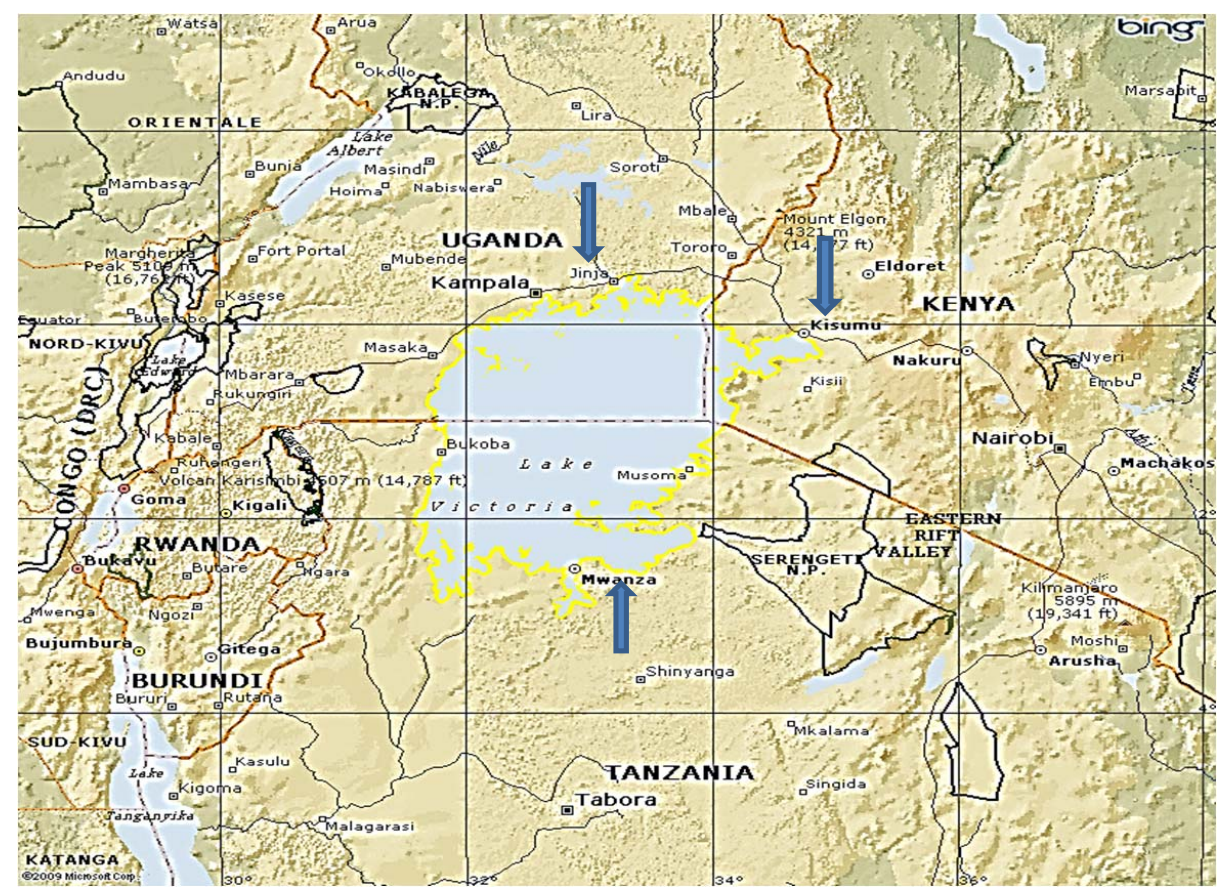

Figure 1. Map of The Lake Basin Showing Location of the Three Areas under Study in their respective countries Marked With Arrows.

\section{Problem statement}

Solid waste management is particularly a problem for urban centres in developing countries. Growing economies and swelling population numbers from both in-migration and natural growth are continually increasing the urban centers' sizes. These large and growing population is one of the main forces driving the centres overwhelming environmental challenges including solid waste management. Key interventions to addressing the solid waste management challenges could lie in the policy arrangements. This chapter therefore seeks to compare the policy arrangement of three urban centres in East Africa in order to conclude on which arrangement(s) presents the most flexible, robust and sustainable option for solid 
waste management. Flexible to include both state and non-state actors, robust to keep on running or operating under changing national circumstances (like the economy) and sustainable to contribute to the improvement of environmental conditions.

\subsection{Profile of the urban centres studies}

Kisumu is the third largest urban center in Kenya after Nairobi and Mombasa. It is located in Nyanza province in the Western part of Kenya. Geologically it sits on the arm of tertiary lava, which extends southwards overlooking the plains to the East and Winam gulf of Lake Victoria to the West. The Lava formation is attributed to the tectonomagnetic activities associated with the Kano-Rift valley system. As a result the city is curved into a trough with the walls of the Nandi escarpment to the East dropping onto the floor of the Kano flood plains and gently flowing to the Dunga wetlands at the shores of the Lake Victoria. Kisumu covers an area of $297 \mathrm{~km}^{2}$ of land mass and $120 \mathrm{~km}^{2}$ under the lake. The population of the council has been increasing rapidly, and at a growth rate of $2.8 \%$ per annum it was estimated at about 500,000 in 2007 from 322,734 people in 1999.

Jinja is the second largest urban center in Uganda after Kampala city. It is located $81 \mathrm{~km}$ East of Kampala. It is situated just north of the equator, on the northern shores of Lake Victoria and at the source of the Nile River. The town lies on a tapering plateau with an average altitude of 1230 meters above sea level. The municipality has an extensive shoreline in the east, south and west of both Lake Victoria and the voluminous waters of the Victoria Nile. It occupies an area of $28 \mathrm{~km}^{2}$. It has a resident population of about 86,512 people (population census 2002) with a day population that doubles that figure due to peri-urban migrant labor. At a growth rate of $2.4 \%$ per annum, the population as of 2007 is estimated at 95,121 people, see [6].

Mwanza is the second largest urban center in Tanzania after the city of Dar-es salaam. It covers an area of $1325 \mathrm{~km}^{2}$ of which $425 \mathrm{~km}^{2}$ is dry land and $900 \mathrm{~km}^{2}$ is covered by water. Of the $425 \mathrm{~km}^{2}$ dry land area, approximately $86.8 \mathrm{~km}^{2}$ is urbanized while the remaining area consists of forested land, valleys, cultivated plains, grassy and undulating rocky hill areas. According to the 2002 National Census, Mwanza City had 476,646 people. With an annual natural growth rate of $3.2 \%$, the population as of 2007 , is estimated at 714,060 people, see [7].

\subsection{Research methodology}

The study makes use of both secondary and primary data. The collection of secondary data involved a review of literature on the concept of policy arrangement; network,state and market governance as well as Bylaws and other legislative pieces in Kenya, Uganda and Tanzania. The study obtained primary data from interviews with urban authority officials (Public health Officers and Director of Environment at Jinja Municipal Council, Public health officers and solid waste manager at Mwanza City Council and Environmental Officers at Kisumu City Council). Non-state service providers both formal and informal in the three urban centres were also interviewed. In addition, about 600 questionnaires were administered to households and given the differences inherent in the three towns, different approaches were taken to select samples for the household survey as follows: 


\section{For Mwanza:}

In Mwanza, there are two districts and each has urban and rural wards. Urban wards (14 in number) were purposively selected because they receive solid waste management (SWM) services. Every urban ward receives services either from a Community Based Organization $(\mathrm{CBO})$ or a private company working under a contract so all urban areas irrespective of income levels receive SWM services [8]. For the survey, stratified sampling was used. It was a disproportionate stratified sampling because for all the 14 urban wards (which were the strata), on average 13-14 households were interviewed irrespective of population figures in each ward. The goal was to have each ward represented by a minimum number of 10 households and to arrive at a maximum total sample of 200 households. Using the population census data and with the help of the ward leaders and the public health officers posted to each ward, households were randomly picked from a list and questionnaires administered.

For Kisumu:

In Kisumu, SWM is patterned much more along income levels. Previous empirical work, see [9], indicated that the council had not officially permitted non-state actors to operate but all SWM activities by these actors went on unofficially. SWM service providers (the non-state actors) defined their clients on the basis of their income. Community self-help groups were common in low income areas while private companies dominated high and middle income areas. Therefore a list of low, middle and high income estates was made, and then a few estates from each of the three categories were randomly picked

NB: Just like in Mwanza, Kisumu has civic wards, some of these wards are estates in themselves for instance, Nyalenda is a ward and an estate at the same time, while in other wards, there is more than one estate. There are in total 17 civic wards covering 41 estates.

There are about 41 estates recognized by the council (11 high income, 17 middle income and 13 low income). The council provides waste management services in only 12 of these estates. The study aimed to administer 200 questionnaires just like in Mwanza. About half the number of estates in each income category mentioned earlier was randomly selected. The study ended up administering questionnaires in 6 high income, 9 middle income and 7 low income estates. About 10 questionnaires were administered in each of the estates selected. The number of households per estate varies from about 3,200 to about 12,000. Selecting households within the selected estates was done differently depending on the kind of estate arrangement. In planned estates like the Railway estates, the houses are numbered and organized in a certain pattern so it was easy to do systematic sampling, selecting every fourth household. In the informal estates like Nyalenda, the houses are not numbered or arranged in any particular order,

the researchers were guided by the village names within Nyalenda which were listed and then one household from each village was randomly selected. To avoid covering a village more than once, the study used one research assistant per estate.

The income categorization used to obtain the sample reflects the general pattern of service provision in the town. The estates were classified according to one of the three distinct in- 
come categories. From each group of estates about half was randomly selected. Within each selected estate about 10 households were randomly selected. Therefore, based on the argument of inferential statistics, the data can be considered to reflect the situation of service provision among the different income categories in the town as a whole

For Jinja:

In Jinja, there are three divisions [6]. Within each division there are parishes but solid waste management services have been contracted out per division and the work is given to two contractors. The divisions are:

- Central Division

- Walukuba Division

- Mpumudde Division

One contractor serves both Central and Walukuba divisions while the other contractor serves Mpumudde division. Service is therefore not structured along income levels as in Kisumu neither per ward as is the case in Mwanza. Waste is collected from skips (collection points) and not directly from the households. Contractors are paid per emptied skip. There are 119 collection points (skips) in Central, 10 in Walukuba and 20 in Mpumudde. Central and Mpumudde Divisions were picked for the study in order to show the differences (if any) in service provided by the two contractors. Frequency of questionnaires administered was higher in Central with about 180 questionnaires randomly distributed and 38 randomly distributed in Mpumudde. These frequencies were more or else in line with the distribution of collection points which are many in Central division. In the end, in total 218 household questionnaires were administered, so the aim to get a total minimum of 200 questionnaires, as for the other two towns, was reached.

With a list of street names (also referred to as roads/avenues/zones which are equivalent of the villages in Kisumu), households (numbering up to 10 in certain streets) were randomly selected from each street.

\subsection{Theoretical framework}

In East Africa, the national state in each country has been and is the predominant actor when it comes to service provision. Recently though, the influence of market and civil society stakeholders is evident particularly in service provision at the local level. In this paper these developments are analysed using the policy arrangement approach developed by Arts and others $[5,10,11]$. As an approach, it has been mainly used in studies conducted in Western countries but can also provide a framework against which solid waste management is analysed in East Africa given the entry of non-state actors. Policy arrangement is defined as the temporary stabilization of the content and organization of a policy domain at a specific level of policy making. It is temporary because arrangements are under pressure of constant change either by policy innovations on the ground or by processes of political modernization. It has four main dimensions namely: 
- The actors and their coalitions involved in the policy domain; and

- The division of power and influence between these actors, where power refers to the mobilization, division and deployment of resources, and influence to who determines policy outcomes and how;

- The rules of the game currently in operation, specifically the formal procedures for pursuit of policy and decision-making; and

- The current policy discourses where the concept of discourse refers to the views and narratives of the actors involved -in terms of norms and values, definitions of problems and approaches to solutions - in this case, the study captures network governance

These four dimensions of a policy arrangement are inextricably interwoven. This means that any change on one of the dimensions induces change on other dimensions. This relationship is symbolized by the tetrahedron, in which each of the corners represents one dimension (Figure. 2).

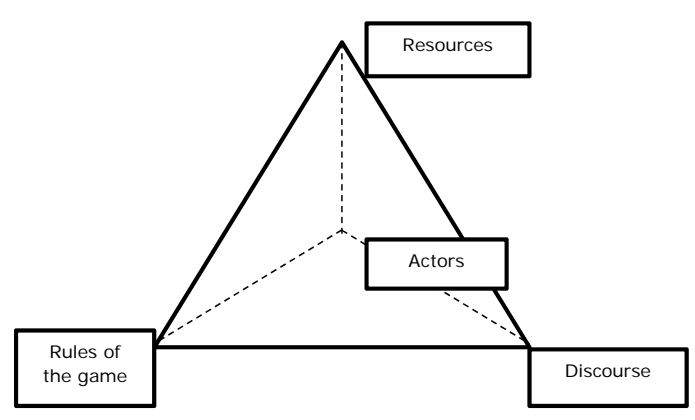

Figure 2. Tetrahedron showing Relation between Dimensions of Policy Arrangement

An analysis of an existing policy arrangement, including its problems or sticking points, concerns all four dimensions of the concept. The methods for mapping out the relevant actors, their coalitions and oppositions are familiar from network analysis. Methods are also available for assessing power relationships. Then existing rules of the game in the arrangement have to be reconstructed: Who decides on the agenda? Who participates in the policy game? Who is excluded? Who takes the decisions? Discourse analysis provides systematic instructions for analyzing the fourth dimension: What are the main concepts in policy discourse and the policy programme? What are the basic assumptions of the policy? What do relevant policy documents contain? How do the various players in the field interpret the policy concepts and basic assumptions?[12].

According to [11], policy innovations can be initiated from each of the dimensions. Policy agents may decide: (1) to allow more or new actors to participate in policy making or in coalition formation; (2) to reshape power relations, for example by adding to or withdrawing resources from a policy arrangement; (3) to reformulate the rules of the game on the basis of which policies are made; and (4) to reformulate the policy discourse concerned, for example by 
redefining its core concepts. However, innovations in one dimension tend to have consequences for other dimensions, and even for the arrangement as a whole. In other words, in some cases changes have been initiated by new coalitions (e.g. the participation of citizen groups), whereas in other cases they are provoked by innovative discourses, or reinforced by rules and resources, setting off a chain reaction of changes in all aspects. Finally, this chain may lead to the change of entire policy arrangements. The approach of policy arrangements helps to analyse such changes.

\subsection{Changing political dynamics in service provision}

The existence and performance of local authorities in East Africa in service provision, has a historical component depicting changes that have occurred dating back to the 1960's when the three East African countries attained independence. Olowu [13] explains that when these countries attained political independence with formal structures of democratic, representative government, political leaders in their bid to consolidate political power then opted for highly centralized modes of governance. This centralized mode of governance was reinforced by a culture of politics of patrimony in which all powers and resources flow from one source of power ('the father of the nation') to clients to shore up the regime. This pattern of power and resource distribution was strongly supported by both domestic and external actors until the late 1980s. The reasons adduced for adopting this approach included-rapid economic and social development actualized through centralized planning, unity and national integration, containment of corruption and political stability. In fact the argument was that if decentralization would be necessary at all it must be in the form of administrative decentralization or deconcentration - the sharing of responsibilities between central and local administrations which do not exercise any discretionary authority nor dispose of resources. Yet the 1990s marked an era of political and democratic approaches wherein decentralization was progressively being seen (by governments, external actors and the increasingly influential civil society lobbies) as a means of enhancing democracy and citizen participation and (by governments and external actors) as a way of reducing the role, and in particular the expenditures, of the central government [14]. Over time, these changes have necessitated governmental reconfigurations, many of which have a powerful 'local' governance orientation. They include resurgent regional organizations, public private partnerships in infrastructure creation and maintenance and service delivery, decentralisation, devolution and deconcentration of expertise and accountabilities within government departments, and contractual relationships between government and community providers, among others [15]. Non-state actors are increasingly getting involved in service provision. To date though, none of the three East African countries has any municipal service that is completely privatized as yet neither are there distinct policies on privatization of service provision within local authorities. The services most experimented with so far are solid waste management and water supply, but the former more than the latter.

\subsection{Existing solid waste management arrangements}

The arrangements of SWM in the three urban centres differ. This is captured within the four dimensions of policy arrangement: 


\subsubsection{Rules}

\subsubsection{Jinja}

Jinja has three administrative divisions: Central, Walukuba and Mpumudde. Due to the efforts to move towards privatization in the country, the council contracted out solid waste management through open bidding, specifically collection and transfer of waste to the disposal site. The arrangement is an annual contract between the municipal council and the private entrepreneurs and in the financial year 2008/2009 two contractors won the tenders [16]. One serves two divisions: Central and Walukuba, while the other contractor provides service to Mpumudde. The legitimacy of the contractors is realized in a number of ways. First the Jinja Solid Waste Management By-Laws 2005, in their objectives recognize the role of private companies in the collection and disposal of waste when this is practiced in a sustainable manner and at a fee. The two contractors serving then were thus officially recognized by the council and in turn by a number of the households they served. Secondly, the tenders for contracts in SWM are advertised through the media and as earlier mentioned, there is open bidding. Contracts for companies that were involved previously can only be renewed on the basis of their performance. As far as decision making is concerned, the municipal authority is still at the helm of SWM, making policies and seeing to their implementation. The contractors do not attend council meetings and are therefore unable to make or influence decision-making. From an interview with one of the contractors however, it became clear that they are free to voice their opinions directly to the town clerk, which may or may not be taken into account when formulating policies.

\subsubsection{Mwanza}

In Mwanza, there are 21 wards, out of which only 14 wards receive solid waste management services. These are the wards in the urban sections of Mwanza city. Privatization of solid waste management resulted in the council awarding contracts to groups and in the financial year 2008/2009, contracts were awarded to Community Based Organizations and two private companies that serve the wards in the Central Business District [7, 16]. Every other ward is served by one or two Community Based Organizations (CBOs). In terms of legitimacy, it should be noted that first, the $\mathrm{CBO}$ and the two private companies are legitimate organizations, officially recognized by the council and the people they serve as revealed by the interviews and household survey. They are awarded formal contracts after having won through a democratic process. The groups undergo registration as solid waste management service providers and pay a registration fee of Tshs25,000 (USD17.85). The private companies pay taxes to the Tanzania Revenue Authority. Secondly these contractors are well known to the people they serve because the members of these $\mathrm{CBO}$ s are local and belong to/are residents in the wards they serve.

\subsubsection{Kisumu}

In Kisumu, even with the municipality as the central locus of authority, see [17], legitimacy remains a key concern. This is so because there are questions regarding the legal mandate accorded to groups providing SWM informally. Most of these informal groups are registered by the ministry in charge of community development, they are however not formally recognized by 
law as actors in the domain of solid waste management. The presence and activities of these groups are nevertheless known by the council and some of these groups (see table 1 below) even responded to be operating through some form of 'franchise ${ }^{1}$ in areas allocated to them by the municipal authority. With no legal papers to show the arrangements they are part of, most if not all of these groups are not legitimate in the SWM arena. This impinges on a number of issues, for instance seeking legal redress in case of payment defaults becomes a problem. Getting donor assistance also becomes a problem because questions will arise as concerning ties to the public, transparency and adherence to the mission of a group, representative status and the relationship between the group and the community served. On the other hand, in terms of community support, openness of information, democratic decision-making, these groups can be considered more legitimate than some official actors are.

\begin{tabular}{lc}
\hline Form of arrangement & Numbers \\
\hline 'Franchise' & 11 \\
\hline Quasi contract & 1 \\
\hline Partnership & 1 \\
\hline Unwritten authority to operate & 2 \\
\hline Pay rent to council & 1 \\
\hline None & 15 \\
\hline TOTAL & 31 \\
\hline
\end{tabular}

Table 1. Legitimacy of groups involved in SWM services Source: Author based on field work

\subsubsection{Actors and coalitions}

\begin{tabular}{lccc}
\hline Town/SWM Status & Jinja & Mwanza & Kisumu \\
\hline $\begin{array}{l}\text { Waste collection } \\
\text { arrangement }\end{array}$ & $\begin{array}{c}\text { Private collectors formally } \\
\text { contracted and the } \\
\text { municipality }\end{array}$ & $\begin{array}{l}\text { CBOs and 2 private } \\
\text { collectors formally } \\
\text { contracted and the } \\
\text { municipality }\end{array}$ & $\begin{array}{c}\text { CBOs, private companies } \\
\text { and operating informally } \\
\text { and the municipality }\end{array}$ \\
\hline $\begin{array}{l}\% \text { of households } \\
\text { receiving SWM service }\end{array}$ & $60 \%(n=218)$ & $82.5 \%(n=200)$ & $46.5 \%(n=200)$ \\
\hline $\begin{array}{l}\% \text { of households that } \\
\text { pay for waste collection }\end{array}$ & N/A & $96.4 \%(n=165)$ & $79.4 \%(n=93)$ \\
\hline $\begin{array}{l}\text { Satisfaction of SWM } \\
\text { amongst households }\end{array}$ & $62.6 \%(n=130)$ & $51 \%(n=165)$ & $70.6 \%(n=93)$ \\
\hline $\begin{array}{l}\% \text { of waste collected in } \\
\text { the towns }\end{array}$ & $40-60 \%$ & $88 \%$ & $35-45 \%$ (municipal and \\
\hline
\end{tabular}

Table 2. Summation of SWM Indicators in the three urban centres Source: Author based on field work

1 The word franchise is in quotation marks because there are no legal papers to show for it and the arrangement is only franchise by name but not in actual sense. 


\subsubsection{Jinja}

Looking at the three urban centres, Jinja's SWM arrangement is a close representation of the model of market and networks. This is because of the presence of economic actors in the SWM arena. It is a close representation because these actors are not exactly the determining players in the field of SWM, yet they provide most of the SWM services to the council and its people. The economic actors are private entities in form of companies with several employees as casuals contracted to provide services. The casuals do the collection and sweeping. There are no coalitions or relations between the companies contracted. Field interviews with these contractors revealed that market competition prevents them from having any form of cooperation. As their contracts have an annual nature, they need to stay on top of the game to win the contract the coming year. Within this arrangement, the percentage of households receiving service stands at $60 \%$ (where $n=218$ ) (see table 2 above).

The networks in this arrangement refer to other actors with shared interests in SWM though the degree of cohesion varies between them. There is the involvement of women and youth groups in the road sweeping and clean-up activities which are done occasionally and mostly on a voluntary basis. There are also environmental groups that are actively involved, including National Environmental Management Authority (NEMA) as a wing of the government which has established pedagogic centers to showcase exemplary activities and is helping to source additional skips to be used in the council. Also involved are international institutions like Lake Victoria Region Local Authorities Cooperation (LVRLAC) who promote exchange of practices amongst the councils member of the organization. International Labour Organization (ILO) and the Lake Victoria Basin Commission (LVBC) have also actively taken part in capacity building.

\subsubsection{Mwanza}

Mwanza's SWM arrangements comes close to that which can be described as communities and networks. They come 'close' to this model because there are questions on extent to which the CBOs involved can exercise power. Although much of the SWM arena is dominated by CBOs (14 in number and 2 private firms) and these CBOs are the major implementers of the SWM policies, the local authority still dictates these policies, awards the contracts and generally steers everything that has to do with SWM. Unlike the situation in Jinja, as far as the contractors relating with each other is concerned, all the 16 groups interviewed in Mwanza belong to an association called the Mwanza Solid Waste Management Association (MASMA). MASMA meets once every month to share ideas on problem solving and opportunities that can be explored further. Apart from the association, neighboring CBOs (that is CBOs working in neighboring wards) work together in sharing experiences and sometimes even the use of equipment in case the workload is more than expected. This arrangement has resulted to $82.5 \%$ (where $\mathrm{n}=200$ ) of households receiving services. As an arrangement it also promotes social sustainability having includes local communities as service providers within their own jurisdictions.

Networks in the Mwanza arrangement are visible in the different actors involved in SWM albeit to different degrees. Apart from the local authority, CBOs and the private companies, 
just like in Jinja, there is NEMA, different government ministries and regional organizations, in particular, LVRLAC to which Mwanza is a member and the LVBC. ILO has been very instrumental in training the CBOs to earn their income from the waste collection and also urging them to form an association.

\subsubsection{Kisumu}

The situation in Kisumu comes close to the model of hierarchy and networks. This is the case because the local authority is still solely responsible for solid waste management and the management style is actually still of the command-and-control type. The Department of Environment receives its directions and authority from the line ministry of Local Government and implements them at the local level. Unlike Mwanza and Jinja, Kisumu has no for$\mathrm{mal} /$ official arrangement that involves non-state actors in collecting and transporting waste or in sweeping the roads. The local authority does the road sweeping itself, as well as the collection, transfer and disposal of waste, but these local authority services are concentrated in the Central Business District and only a few residential areas also benefit from them. Non-state actors ( see table 3 below) provide service to most of the other residential areas in an unofficial manner. This is likely to affect the robustness of the system as the non-state actors cannot be held accountable for the SWM services they provide.

\begin{tabular}{lcc}
\hline SWM & Existing Numbers & Numbers Interviewed \\
\hline Recyclers & 23 & 6 \\
\hline Groups: CBOs and youth groups & 27 & 17 \\
\hline Private companies/individuals & 18 & 8 \\
\hline TOTAL & 68 & 31 \\
\hline
\end{tabular}

Table 3. SWM Groups in Kisumu City Council and Those Interviewed Source: Field work in Kisumu

In terms of relationships between the non-state actors themselves, the study revealed that they work together during cleanups and some even share their working equipment. Like in Mwanza, they have also formed an association called the Kisumu Waste Managers Association. This arrangement has resulted to $46.5 \%$ (where $n=200$ ) of households receiving services (see table 4 below for the percentage of service coverage provided by the different actors).

\begin{tabular}{lcc}
\hline Service provider & Frequency & Percentage \\
\hline CBO & 21 & 10.5 \\
\hline Municipality & 18 & 9.0 \\
\hline Private Company & 54 & 27.0 \\
\hline Others & 107 & 53.5 \\
\hline & 200 & 100.0 \\
\hline
\end{tabular}

Table 4. Service providers to Households in Kisumu N=200 Source: Household survey in Kisumu. 
Just like the other two towns, the networks refers to occasional involvement of other actors like NEMA, LVRLAC, LVBC, UN-Habitat, Practical Action amongst others.

\subsubsection{Resources}

\subsubsection{Jinja}

In Jinja, the interviews with public health officers revealed that the municipal authority has a budget for SWM which is mostly funded by the central government. There are also fees collected from business premises (Ugshs20,000 - USD14 per business) ${ }^{2}$ and a dumping fee at the disposal site but all these go to the central reserve at the council where they tend to be absorbed by overall council expenditures. The Director of Environment informed that the authority actually has relative autonomy in putting up its own budget, see [18]. Yet it is evident that because most of the funds come from the central government and they are conditional, it is unlikely that adequate resources would be set aside for waste management compared to other 'important' municipal services. For the year 2008, the budgeted expenditure for waste management was Ugshs69,600,000 (USD49,714) but the actual expenditure came to Ugshs120,000,000 (USD85,714) reflecting a deficit of about Ugshs50,000,000 (USD35,714) on the budget.

Payments from the local authority to the contractors are made as per the number of skips emptied to the disposal grounds. The contractor earns Ugshs28,000 (USD20) per small skip (3 tons) emptied and Ugshs30,000 (USD21.4) for a bigger skip (3.5 tons) emptied. On average the contractor serving the two divisions empties 18 skips per day while the one serving Mpumudde division empties on average 7 skips per day. In addition, the contractors use local authority vehicles for transporting the skips to the dumpsite. They hire the vehicles at Ugshs100,000 (USD71.43) per truck per month. They cover the costs for minor and major repairs and fuel as well. The drivers of the trucks are however employed by the local authority and not by the contractors themselves. This is to allow the authority to control and monitor the disposal of waste because the contractor is paid as per the number of skips emptied. One outstanding aspect of the Jinja arrangement which is not the case for Mwanza and Kisumu (and which is also contrary to the 'markets' arrangement), is that households do not pay for the service. The reticence to pay for SWM is because households are convinced that it is the responsibility of the council to provide the service and at no cost. This conviction remains very strong so that attempts to introduce a fee of Ugshs.2000 (USD1.42) per household per month were not successful. This is likely to affect the robustness of service provision as a fee on waste could probably have been ringfenced and used on SWM instead of entirely relying on transfers from central government. given that the Service satisfaction from the household survey stands at $62.6 \%$ (where $n=130$ ).

\subsubsection{Mwanza}

In Mwanza, the study learned that the council also gets most of its SWM funds from the central government. There are additional funds from the fee charged at the dumping site and also from the fee charged to $\mathrm{CBO}$ to have their waste transferred to the dumping ground 
but like in Jinja, these funds end up at the central reserve in the local authority. The solid waste manager informed the study that SWM is not properly defined in the authority's overall budget but that their total expenditures for the year 2007 went up to Tshs210,900,000 (USD150,643). This figure like the one in Jinja is small compared to the expenditures in Kisu$\mathrm{mu}$ and this could be linked to the fact that the costs incurred in Jinja and Mwanza are shared by the council and the private sector contracted to provide SWM services.

The contractors in Mwanza charge different rates for SWM for different land uses but all households pay a standard fee of Tshs400 (USD0.28) per household per month. From the survey $96.4 \%$ (where $\mathrm{n}=165$ ) of households pay for waste collection. Interestingly though only $51 \%$ of these are satisfied with service provision. Possible reasons for this could be that the largest percentage of service providers are CBOs who, as it emerged from the field interviews, have no incentive to invest and improve SWM given that it is an annual contract. This could impact on their level of professionalism. It is also possible that the population has very high levels of expectation about the performance of the contractors. A number of the households gave recommendations in line with improving the skills of CBOs, improving the infrastructure used for collection, showing that they expect more than they are receiving.

The CBOs pay Tshs8000 (USD5.7) per trip to the local authority for transferring waste to the disposal grounds. The private companies however take their own waste to the disposal grounds and pay for its disposal. In addition, the CBOs and the private companies that have been awarded the SWM contracts are paid by the city council at a rate of USD1.2 for every $300 \mathrm{~m}$ length of tarmac road that is cleaned daily.

\subsubsection{Kisumu}

For Kisumu, SWM receives its funds from a conservancy fee of USD 0.67 charged per household per month through the water bill, but this includes only those households that have metered water connection (that is connected to the central grid). There are also other funds originating from the dumping fee charged at USD1.4 per load of a pick-up truck. Businesses, particularly the markets and other commercial areas, are charged for SWM through their business license. The other percentage of funds for SWM comes from what is transferred from the national government to the local authority - the Local Authority Transfer Fund (LATF). All these contributions combined are however, not sufficient to adequately run the SWM system for the municipality as a whole. In the financial year 2006/07, the annual income from solid waste management was USD70,000 against an annual expenditure of about USD420,000.

Kisumu's scenario differs from the other two urban centres when it comes to the payment systems. The areas that are served by the local authority have their costs taken care of in the water bill and some of the households responded that they pay for waste as part of their house rent. The private companies are operating in open competition and work purely on a willing-buyer-willing-seller basis. From the survey, their services are mostly offered in high and middle income estates. Payments are made at the end of the month as per a verbal agreement with the household. CBOs who operate mostly in middle and low income areas also charge fees agreed upon with each household. Given the high number of informal oper- 
ators, fees charged for waste collection varies but the average fees for different residential areas are revealed through the household survey as shown in table 5 below.

\begin{tabular}{lc}
\hline Residential area & Payment rates (Kshs./Month) \\
\hline Low income areas & $40.00-100.00$ (USD) \\
\hline Middle income areas & $150.00-250.00$ (USD) \\
\hline High income areas & $250.00-500.00$ (USD) \\
\hline
\end{tabular}

Table 5. Payment Rates for SWM services. Source: Household Field Survey in Kisumu

The survey revealed that $79.4 \%$ (where $n=93$ ) pay for waste collection and the service satisfaction from these households stands at $70.6 \%$.

\subsubsection{Discourse}

When collecting primary data, there was a lot of hype from the local authority officers regarding privatization of solid waste management services. This was particularly the case in Mwanza and Jinja where non-state actors have been formally involved in service provision. The term privatization has been applied to three different methods of increasing the activity of the private sector in providing public services: 1) private sector choice, financing, and production of a service;2) public-sector choice and financing with private sector production of the service selected; 3) and deregulation of private firms providing services. In the first case, the entire responsibility for a service is transferred from the public sector to the private sector, and individual consumers select and purchase the amount of services they desire from private providers. For example, solid-waste collection is provided by private firms in some communities. The second version of privatization refers to joint activity of the public and private sectors in providing services. In this case, consumers select and pay for the quantity and type of service desired through government, which then contracts with private firms to produce the desired amount and category of service. Although the government provides for the service, a private firm carries out the actual execution of it. The government determines the service level and pays the amount specified in the contract, but leaves decisions about production decisions to the private firm. The third form of privatization means that government reduces or eliminates the regulatory restrictions imposed on private firms providing specific services. The cases studied are neither here nor there as far as privatization is concerned and therefore based on discussions presented in [3], the paper settles on network governance to describe the desirable direction for the arrangements in the three urban centres. A network approach to governance is decentring the state as the unique organ for governance and replacing it with pluricentric forms of governance. Networks permit inter-organizational interactions of exchange, concerted action, and joint production in a formal or informal manner. These networks vary in composition from domain to domain, but they are likely to consist of government agencies, key legislators, pressure groups, relevant private companies and civil society organisations such as NGOs and CBOs [19]. Also citizens themselves may be engaged in such network arrangements but this has to be achieved 
through constructive reciprocities, as they can not be forced through formal state interventions. This network perspective shows many similarities with the popular notion of partnerships in governance seeking to determine the respective roles of public as well as private actors in collaborating to improved public services [20]. Network governance arrangements intend to achieve their objectives through the combined efforts of these different sets of actors, but the respective roles and responsibilities of the actors involved remain distinct while the state is no longer the sole locus of authority. This is however not the case in the three urban centres where the state is still the locus of authority. Yet given the outcome of the surveys and interviews, network arrangement is a desirable option because its flexibility allows diverse social actors to engage actively in finding concrete options for providing sustainable solid waste management services and does not force them to wait until national and urban state authorities are willing and able to engage.

\section{Conclusion}

The policy arrangements for waste management in the three urban centres are different. The one in Jinja typifies an arrangement in which the market dominates. Here, private collectors are formally contracted to provide service with some assistance from the municipal authority. The arrangement in Mwanza is community dominated with more than 14 CBOs and 2 private collectors formally contracted to provide service with some assistance from the city authority. In Kisumu, the urban authority itself solely provides waste management services. The involvement of non- state actors in Kisumu is unofficial and informal. Jinja and Mwanza arrangements are not privatized per se but looking at the official involvement of nonstate actors and the outcome of the household survey in terms of quantities of waste collected, percentages of households covered and SWM satisfaction amongst households in these two towns, the chapter concludes that a balanced arrangement is needed where all societal actors can play their role. It is clear that involving non-state actors as in a network governance arrangement is truly plausible and these actors, both formal and informal, need to work under an effective and strengthened government in order to afford all income groups access to solid waste management services and to ensure flexibility and robustness of the services provided. This means solid waste management services cannot be left to the state actors only. The collective effort by all actors in therefore is likely to ultimately contribute to sustainable management of the Lake Basin. Since the three towns border the Lake Victoria, proper waste management by both the state and non-state actors in respective towns is expected to contribute to the total reduction of the pollution load into the lake waters.

\section{Author details}

Christine Majale-Liyala

Environmental Planning And Management, Kenyatta University, Nairobi, Kenya 


\section{References}

[1] Callaghy, T. 1993. Political Passions and Economic Interests; Economic Reform and Political Structure in Africa. In: Mkandawire, T. Thinking About Developmental States in Africa. A paper Presented at the UNU-AERC Workshop on Institution as and Development in Africa. Tokyo-Japan: UNU Headquarters; 1998.

[2] Lewis, P. Economic Reform and Political Transition in Africa: The Quest for a Politics of Development. World Politics 1996;49 (1) 92-129.

[3] Oosterveer, P. Urban environmental services and the state in East Africa; between neo-developmental and network governance approaches. Geoforum 2009; 40 ( 6) 1061-1068.

[4] Joshi, A. and Moore, M. Institutionalised Co-production: Unorthodox Public Service Delivery in Challenging Environments. The Journal of Development Studies 2004; 40( 4) 31-49.

[5] Arts, B. and Tatenhove, J. Environmental Policy Arrangements: A New Concept. In: Goverde, Henri, (eds.) Global and European Polity? Organizations, policies, contexts. Aldershot: Ashgate; 2000. p 223-237.

[6] Jinja Municipal Council. 2007.Brief Profile of the Municipality. Jinja Municipal Council, Uganda.

[7] Mwanza City Council. 2007. Mwanza city Brief profile. Mwanza City Council, Tanzania.

[8] Mwanza City Council-Refuse Collection and Disposal By-laws of 2000. Mwanza City Council, Tanzania.

[9] Majale, C. L. Modernising Solid Waste Management at Municipal Level: Institutional Arrangements In Urban Centres of East Africa. PhD thesis. Wageningen University The Netherlands; 2011.

[10] Tatenhove, J., Arts, B. and Leroy, P. editors. Political Modernisation and the Environment. The Renewal of Environmental Policy Arrangements. Dordrecht/Boston/ London, Kluwer Academic Publishers; 2000.

[11] Tatenhove, J. and Pieter Leroy, P. Environment and participation in a Context of Political Modernisation. Environmental Values 2003; 12 (2003) 155-74

[12] Bas, A., Leroy. P and Tatenhove, J. Political Modernisation and Policy Arrangements: A Framework for Understanding Environmental Policy Change. Public Organization Rev 2006 ;6: 93-106

[13] Olowu, D. Governance, Institutional Reforms and Policy Processes in Africa In: Olowu D. and Sako S. (eds.) Better Governance and Public policy: Capacity Building for democratic Renewal in Africa. Bloomfield: Kumarian Press ; 2002. p 53 
[14] Conyers, D. Decentralization and Service Delivery: Lessons from Sub-Saharan Africa. IDS Bulletin 2007; 38 ( 1) 18-32.

[15] Olukoshi, A. Changing Patterns of Politics in Africa. In: Boron, A.; Lechini, G. (eds). Politics and Social Movements in a Hegemonic World: Lessons from Africa, Asia and Latin America. Buenos Aires: CLACSO; 2005.p177-201. Retrieved from- http://bibliotecavirtual.clacso.org.ar/ar/libros/sursur/politics/Olukoshi.rtf

[16] Mwanza City Council. Mwanza City Tender Document 2008/2009. Mwanza City Council, Tanzania

[17] Republic of Kenya, 1998 - Local Government Act Cap 265. Revised Edition. Nairobi: Government Printers.

[18] Government of Uganda- Local Government Act Cap 243. Kampala: LDC Publishers.

[19] Keeley, J. and I. Scoones. Understanding environmental policy processes; a review. IDS Working Paper 89. Surrey: Institute of Development Studies University of Sussex; 1999.

[20] Baud, I., Post, J., and Furedy, C. editors. Solid Waste Management and Recycling. Actors, Partnerships and Policies in Hyderabad, India and Nairobi, Kenya. Dordrecht, Boston, London: Kluwer Academic Publishers; 2004 
